\title{
Studies on the Localization of Newly Added Membrane in Growing Neurites
}

\author{
E. L. FELDMAN, D. AXELROD, M. SCHWARTZ, A. M. HEACOCK, \\ and B. W. AGRANOFF
}

Neuroscience Laboratory and Biophysics Research Division, University of Michigan, Ann Arbor, Michigan 48109

Received October 8, 1980; revised May 28, 1981

\begin{abstract}
SUMMARY
Explant culture of the adult goldfish retina results in vigorous neuritic growth, provided that the optic nerve has been previously crushed in vivo. The site of new membrane addition in these growing neurites was studied with a membrane-binding lectin Concanavalin $\mathrm{A}$ (Con $\mathrm{A}$ ) in conjunction with a fluorescent indirect antibody method. Explant cultures were labeled with Con A, followed by rabbit antibodies to Con $A$. This treatment was shown to immobilize Con A receptors while permitting growth. Twenty-four hours later, the washed preparation was treated with fluorescent goat antirabbit antibodies. The bound fluorescent antibodies appeared as a pattern of contiguous fluorescent speckles confined to the area of old growth while regions near the distal end of the neurite were not fluorescent. These results are compatible with the hypothesis that new membrane is added in the region of the growing tip of the neurite.
\end{abstract}

\section{INTRODUCTION}

When a nerve cell is in the process of active extension, a characteristic organelle appears at the growing tip-the growth cone. An important question relevant to our understanding of motility, growth, and differentiation is how new plasmalemmal membrane is added during growth. The question is addressed most advantageously in culture, where neurites and growth cones can be observed best and exposed to experimental probes. Using cultures of rat sympathetic ganglia, Bray (1970) previously demonstrated that carmine and glass particles placed on neurites remain stationary during neurite growth. This observation, together with the fact that neurites leave a "time trace," i.e., do not move once they have been laid down, is suggestive that external membrane addition takes place in the region of the growth cone.

A useful in vitro model of nerve elongation is the stimulated outgrowth from goldfish retinal explants following a previously administered optic nerve crush (Landreth and Agranoff, 1979). We have demonstrated that the lectin Concanavalin A (Con A) specifically binds to glycoconjugates of neurites of ganglion cells growing out from the retinal explants (Feldman, 1979; Feldman, Heacock, and Agranoff, 1978). The use of Con A is reported here as a cell surface marker to infer the location of new membrane addition during growth. A preliminary report of this work has appeared (Feldman et al., 1979). 


\section{MATERIALS AND METHODS}

Common goldfish Carassius auratus were purchased from Ozark Fisheries (Stoutland, MO) and maintained in constant light at $21 \pm 1^{\circ} \mathrm{C}$ in aerated aquaria.

\section{Surgical procedures}

Fish which weighed 7-11 g were anesthetized with $0.02 \%$ Finquel (MS-222, tricaine methanesulfonate, Ayerst Laboratories, New York). The right optic nerve was crushed intraorbitally by first gently cutting the extraocular muscles and then pulling the eye forward in the orbit to expose the optic nerve. The nerve was then crushed with forceps, taking care to leave the surrounding dural sheath intact. If bleeding occurred upon crush, the fish was discarded.

\section{Preparation of goldfish retinal explants}

Ten to fourteen days after the crush, the retina was removed under sterile conditions as previously described (Landreth and Agranoff, 1979) and chopped into $500-\mu \mathrm{m}$ squares on a Mcllwain tissue chopper (Brinkman Instruments, Des Plaines, IL). The retinal bits were explanted to the substratum, which was either a $22-\mathrm{mm}$ No. 1-1/2 square coverslip (Corning Glass, Corning, NY) or a No. 1-1/2 33-mm round coverslip (Hausser Scientific, Blue Bell, PA), each pretreated with polyL-lysine (type VI-B, Sigma Chemical Co., St. Louis, MO) according to Letourneau (1975). Coverslips had been glued previously with Sylgard 182 encapsulating resin (Dow Corning, Midland, MI) over drilled-out bottoms of $35-\mathrm{mm}$ Falcon dishes (Falcon Plastics, division of Becton and Dickinson Laboratories, Los Angeles, CA).

L-15 (Leibovitz) tissue culture medium (Grand Island Biological Company, Grand Island, NY) was supplemented with $9 \%$ fetal calf serum (Flow Laboratories, Rockville, MD), $20 \mathrm{~m} M$ Hepes, $\mathrm{pH}$ $7.2\left(N\right.$-2-hydroxyethylpiperazine- $N^{\prime}$-2-ethanesulfonic acid), $100 \mu \mathrm{g} / \mathrm{mL}$ gentamicin sulfate, $0.1 \mathrm{~m} M$ fluorodeoxyuridine, and $0.2 \mathrm{~m} M$ uridine (Sigma).

Twelve to sixteen bits of retina were placed in each dish and approximately $0.5 \mathrm{~mL}$ of supplemented L-15 was added, enough to cover the bits but not to float them free. Cultures were grown at ambient temperature $\left(20-22^{\circ} \mathrm{C}\right)$ in humid chambers.

\section{Neurite growth and lateral mobility measurements}

Neurites were labeled with rhodamine-conjugated Con A (Rh-Con A) or with Rh-Con A followed by rabbit immunoglobulins to $\mathrm{Con} A$ (anti-Con A) as described for membrane addition studies. Lateral mobility of Con A receptors was measured quantitatively as a time-dependent change in the distribution of unbleached fluorescence-marked Con A receptors following irreversible laser photobleaching of most of the fluorescence in a local region (Axelrod et al., 1976; Thompson and Axelrod, 1980). The local photobleached region had the shape of a thin line transverse to a fascicle $\left(0.5 \mu \mathrm{m} e^{-2}\right.$ Gaussian half-width, $\left.\lambda=514.5 \mathrm{~nm}\right)$ produced by a cylindrical lens placed just before the epi-illuminator field diaphragm. The average lateral diffusion coefficient is given by $D=$ $3 w^{2} f \gamma / 4 t_{1 / 2}$, where $w$ is the $e^{-2}$ intensity half-width, $f$ is the fraction of the fluorophores which are laterally mobile, $t_{1 / 2}$ is the time required for half-recovery of fluorescence, and factor $\gamma$ (a bleaching depth correction) is 1.3 in the present studies.

In order to examine the effect of Con A-anti-Con A treatment on the mobility of other membrane glycoproteins, cultures were incubated with unlabeled Con A followed by anti-Con A as described below. After the last rinse, $50 \mu \mathrm{g} / \mathrm{mL}$ of rhodamine-conjugated wheat germ agglutinin (Rh-WGA) was applied for $30 \mathrm{~min}$ and WGA receptor mobility was determined following photobleaching.

For determination of the effects of Con A on neurite growth, explants were treated with Con A/ anti-Con $\mathrm{A}$ as described below for fluorescent labeling experiments. The extent of neurite fascicle growth was measured by superimposition of sequential low-magnification ( $4 \times$ objective) dark-field photomicrographs of 2-3 day explants. Projected images from Con A treated and untreated cultures were traced in different colors for each time point $(0,3,6,12$, and $24 \mathrm{~h})$. Elongation in each field (30-50 fascicles) for a given time interval was determined with a map measuring wheel.

\section{Membrane addition studies}

Con A, Rh-Con A, fluorescein-conjugated Con A (FITC-Con A), Rh-WGA, and anti-Con A were purchased from Vector Laboratories (Burlingame, CA). Rhodamine-conjugated $\mathrm{F}\left(a b^{\prime}\right)_{2}$ fragment goat antirabbit IgG (Rh-goat antirabbit IgG) was a product of Cappel Laboratories (Cochranville, PA).

In the following experiments, only unsupplemented L-15 was used. The medium of 3-day cultures 
was removed; the cultures were rinsed three times in L-15, $10 \mathrm{~min}$ per rinse, to remove medium glycoproteins, and incubated with L-15 containing either 10 or $25 \mu \mathrm{g} / \mathrm{mL}$ of Con A. After $30 \mathrm{~min}$ the dishes were rinsed with fresh L-15 and incubated in $100 \mu \mathrm{g} / \mathrm{mL}$ of the anti-Con A in L-15. Cultures were rinsed after $30 \mathrm{~min}$ as described above, and at the end of the third rinse, the time was recorded and designated as $T_{0}$. The cultures were placed in a humid chamber for $24 \mathrm{~h}$, at which time the unsupplemented L-15 was replaced by $200 \mu \mathrm{g} / \mathrm{mL}$ of Rh-goat antirabbit IgG in L-15. After a 30-min incubation, the cultures were rinsed three times with fresh L-15, and the time recorded as $T_{24}$. All lectin and antibody incubations were performed at ambient temperature $\left(20-22^{\circ} \mathrm{C}\right)$.

Cultures were observed with phase and fluorescence optics (Leitz Diavert, rhodamine Ploempak filter system M No. 513421; 50-W high-pressure mercury lamp) with a Zeiss $40 \times$ water immersion objective ( 0.75 numerical aperture). Phase photographs were taken at $T_{0}$ and $T_{24}$ while fluorescence photographs were taken at $T_{24}$.

A similar protocol was used in two other experiments. Cultures were tagged with Rh-Con A followed by anti-Con A using the standard binding procedure. At $T_{0}$, the cultures were placed in a light tight box for $24 \mathrm{~h}$. In this paradigm, phase and fluorescence pictures were taken at $T_{0}$ and 24 h later.

In another protocol, cultures were treated with Con $\mathrm{A}$ and anti-con $\mathrm{A}$, and $24 \mathrm{~h}$ later, with the Rh-goat antirabbit IgG, but at the end of the final rinse, $100 \mu \mathrm{g} / \mathrm{mL}$ of FITC-Con A in L-15 was added to the cultures for $30 \mathrm{~min}$ at room temperature. After three $10-\mathrm{min}$ rinses in fresh L-15, the cultures were assayed for both fluorescein and rhodamine fluorescence with appropriate Ploempak filter cubes.

\section{RESULTS}

For Con A to be a suitable cell surface marker with which preexisting membrane can be distinguished from newly added membrane, conditions must be defined in which it is neither toxic nor diffusible. Con A receptors on the neurite membrane reach saturation at approximately $200 \mu \mathrm{g} / \mathrm{mL}$ of Rh-Con A (Feldman, 1979). Subsaturating doses ( 10 or $25 \mu \mathrm{g} / \mathrm{mL}$ ) were chosen for the present studies to minimize possible toxic effects. Fluorescence photobleaching (Fig. 1) shows that Con A receptors treated with only $10 \mu \mathrm{g} / \mathrm{mL}$ of Rh-Con A can redistribute diffusely into a small selectively photobleached region. As might be predicted from lateral mobility studies in other systems (Edelman, 1976), Con A receptors treated with $10 \mu \mathrm{g} / \mathrm{mL}$ of Rh-Con A followed by $100 \mu \mathrm{g} / \mathrm{mL}$, of anti-Con A become almost immobilized, while the fluorescent labeling pattern become speckled in appearance. Crosslinking of a portion of the Con A receptors did not inhibit the mobility of wheat germ agglutinin receptors [average diffusion coefficient $\left.=(0.8 \pm 0.2) \times 10^{-10} \mathrm{~cm}^{2} / \mathrm{s}\right]$, a result compatible with the conclusion that there were minimal effects on other membrane constituents.

Measurements of neurite fascicle lengths in untreated cultures in two separate experiments gave a relatively reproducible growth rate of $14.6 \pm 0.6 \mu \mathrm{m} /$ neurite $/ \mathrm{h}$ ( \pm S.E.M., $n=26$ ). Analysis of the effects of addition of $10 \mu \mathrm{g} / \mathrm{m} /$ Con A, followed by $100 \mu \mathrm{g} / \mathrm{mL}$ anti-Con A reveals no detectable retardation of neurite growth after $24 \mathrm{~h}$. These observations indicate that Con A/anti-Con A fulfills the criteria for use as a cell surface marker which will permit examination of the site of new membrane addition in growing neurites as described in the following experiments.

In one treatment paradigm, a culture first was labeled with Con A/anti-Con A, permitted to grow for $24 \mathrm{~h}$, and then exposed to fluorescent goat antirabbit IgG. The latter would be expected to bind only to surface membrane existing at $T_{0}$ and not to membrane added during the $24-\mathrm{h}$ interval. The $T_{0}$ phase photomicrograph served as a record of growth in a defined field at the time of lectin/antilectin treatment, while the $T_{24}$ phase photomicrograph indicated where new growth had occurred (Fig. 2). The $T_{24}$ fluorescence photomicrograph shows bright, contiguous fluorescent speckles confined to the region of initial 

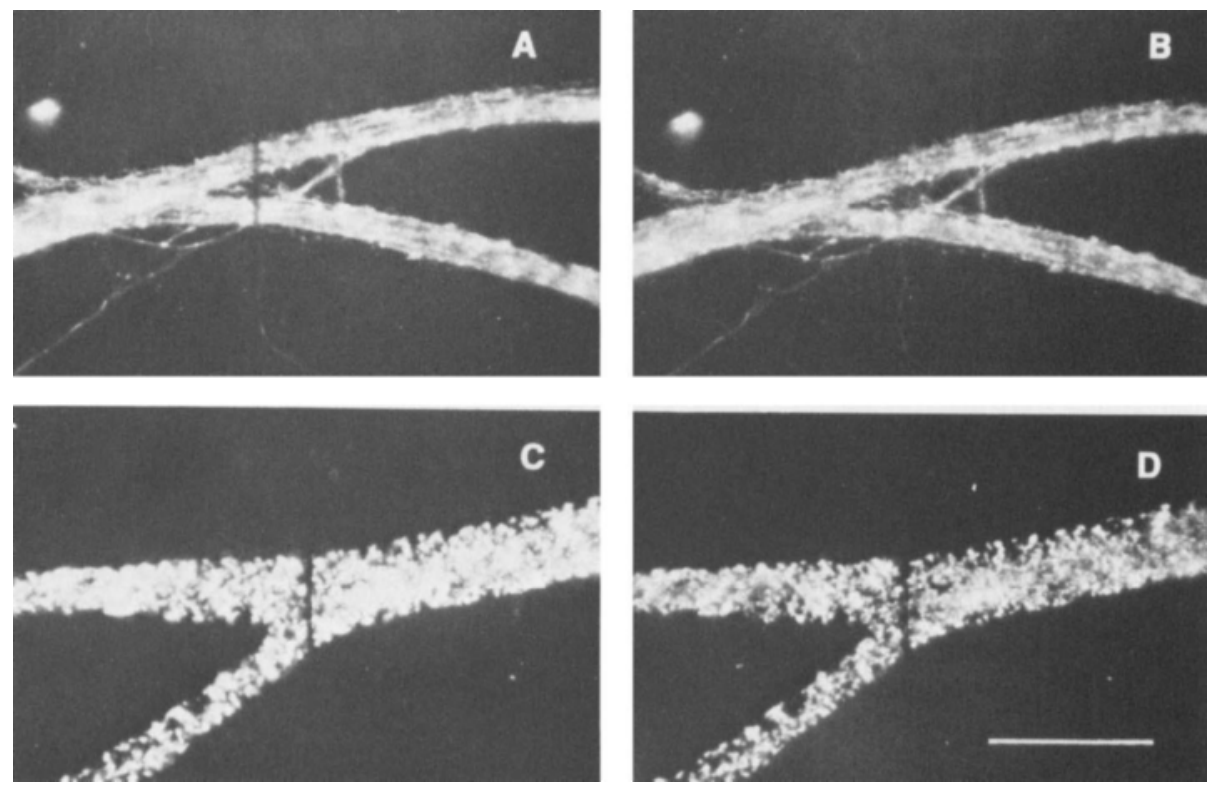

Fig. 1. Lateral mobility of Con A receptors. (A) Exposure taken immediately after local photobleaching by a focused stripe transverse to a fascicle treated with $10 \mu \mathrm{g} / \mathrm{mL}$ of $\mathrm{Rh}$-Con A. (B) Same field as (A), exposure taken 10 min later. Average diffusion coefficient $D=(1.0 \pm 0.1) \times 10^{-10}$ $\mathrm{cm}^{2} / \mathrm{s}( \pm$ S.E.M., $n=11$ ). (C) Exposure taken immediately after local photobleaching on a fascicle treated with $10 \mu \mathrm{g} / \mathrm{mL} \mathrm{Rh}$-Con A followed by $100 \mu \mathrm{g} / \mathrm{mL}$ of anti-Con A. (D) Same field as (C), exposure taken $10 \mathrm{~min}$ later. $D=(0.11 \pm 0.08) \times 10^{-10} \mathrm{~cm}^{2} / \mathrm{s}$. Bar $=50 \mu \mathrm{m}$.

growth. Areas of new growth remained unlabeled. The striking correspondence of the $T_{24}$ fluorescence picture to the $T_{0}$ phase photomicrograph indicated that the fluorescence distribution represented preexisting membrane. The result suggests that newly added membrane had emerged from the old growing tips.

Similar observations were made when the second addition paradigm, Rh-Con A followed by anti-Con A, was used. In this instance, not only a phase but also a fluorescence picture could be taken immediately after the Rh-Con A/anti-Con A incubation; both pictures were superimposable. The fluorescence picture taken $24 \mathrm{~h}$ after the incubation was also superimposable with the initial phase, and fluorescence micrographs but not with the 24 -h phase picture again suggesting that the unlabeled, newly added growth emerged from the tip of the neurite fascicle (Fig. 3).

With both experimental protocols, the question arises as to whether the unlabeled fibers seen at $T_{24}$ might have escaped lectin binding at $T_{0}$. This appears unlikely, since we have found all fibers visible by phase microscopy to bind lectin. Electron microscopic studies (Feldman, 1979; Feldman, Heacock, and Agranoff, submitted) indicate localization of ferritin-labeled lectin throughout fascicles at the axolemma surface.

When growth cones are labeled with fluorescent Con A alone or with the indirect antibody technique, they may or may not show intense labeling as seen in Figures 2(B), 2(E), and 2(H) (Feldman, 1979). In the present experiments, this bright fluorescence remains after $24 \mathrm{~h}$ in the $T_{0}$ growth cone area, even though the neurite has advanced. This is a reflection of the immobilizing nature of the lectin-antibody treatment at $T_{0}$ and does not necessarily indicate that the treatment has altered neurite outgrowth. 

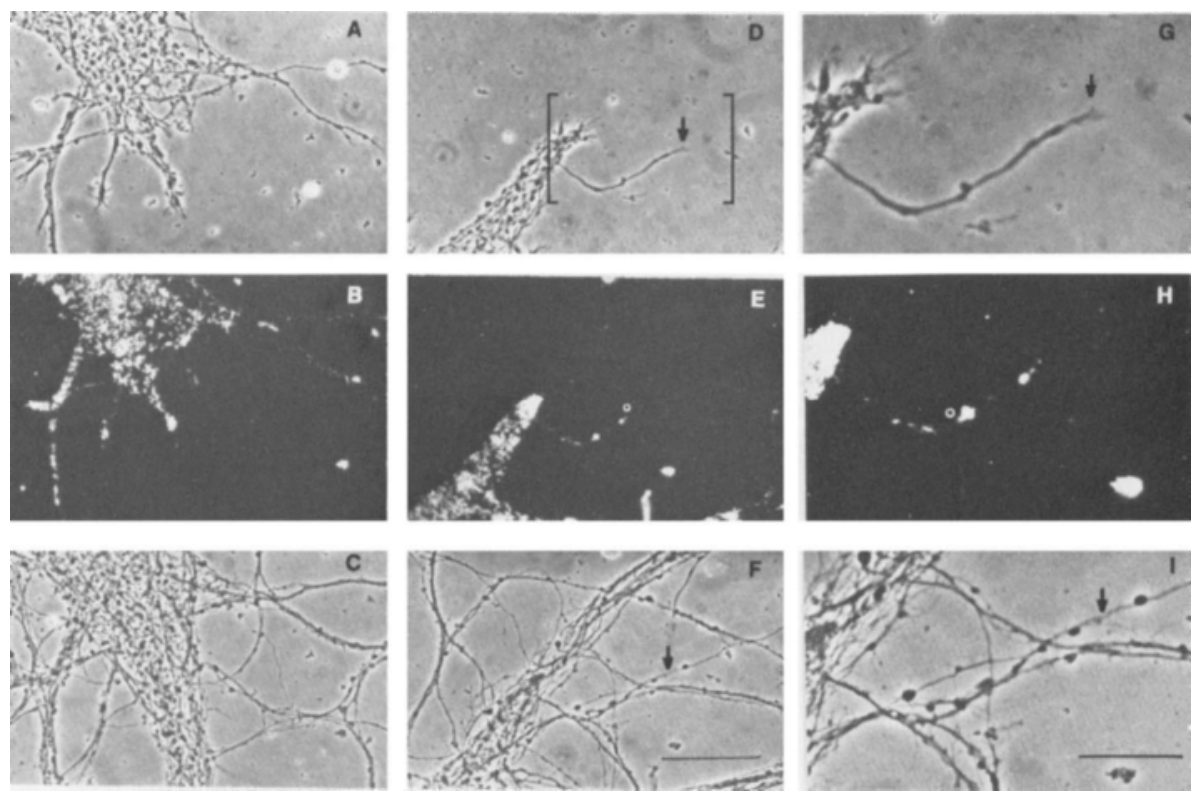

Fig. 2. Visualization of the addition of new neurite membrane with Rh-goat antirabbit IgG. (A) Phase contrast photomicrograph of neurites incubated with $25 \mu \mathrm{g} / \mathrm{mL}$ of Con A followed by 100 $\mu \mathrm{g} / \mathrm{mL}$ of anti-Con A. (B) Fluorescent photomicrograph of the same area $24 \mathrm{~h}$ later after treatment with Rh-goat antirabbit antibodies. (C) Phase contrast photomicrograph of (B) showing extent of 24-h growth. (D) Phase contrast photomicrograph of neurites incubated with $25 \mu \mathrm{g} / \mathrm{mL}$ of Con A followed by $100 \mu \mathrm{g} / \mathrm{mL}$ of anti-Con A. (E) Fluorescent photomicrograph of the same area $24 \mathrm{~h}$ later after treatment with Rh-goat antirabbit antibodies. (F) Phase contrast photomicrograph of (E) showing extent of 24-h growth. Bar $=60 \mu \mathrm{m}$. (G), (H), and (I) Enlargement of area indicated in (D), (E), and (F), respectively. Registration arrows mark position of growth cone at $T_{0}$. Bar $=$ $20 \mu \mathrm{m}$.

In a variation of the first addition method, after the cultures had been incubated with Rh-goat antirabbit IgG, they were tagged with FITC-Con A. Color photomicrographs (not shown) reveal that the region of the growing tip shows only fluorescein fluorescence, indicating that the newly added membrane does contain Con A receptors. Preexisting membrane exhibited intense fluorescein in addition to rhodamine fluorescence, as would be expected from FITC-Con A binding to the surface Con A receptors not previously bound by the subsaturating dose of Con $\mathrm{A}$ and to the carbohydrate moieties of the immunoglobulins.

\section{DISCUSSION}

Central nervous system neurons are generally believed to survive for the life of the organism, maintaining cellular morphology of both soma and neuronal processes for long periods of time. Since there is also ample evidence that neuronal components, including membrane proteins and lipids turn over with half-lives of days or weeks, it is apparent that the structural components of the cell (other than DNA) are in a constant state of replacement by a process that preserves form. For the axon and nerve ending, the replacement of plasma membrane constituents takes on additional complexity due to the need for such components to be transported from the cell body, often over great distances, before insertion at their final destination. In actively growing neuronal processes, 

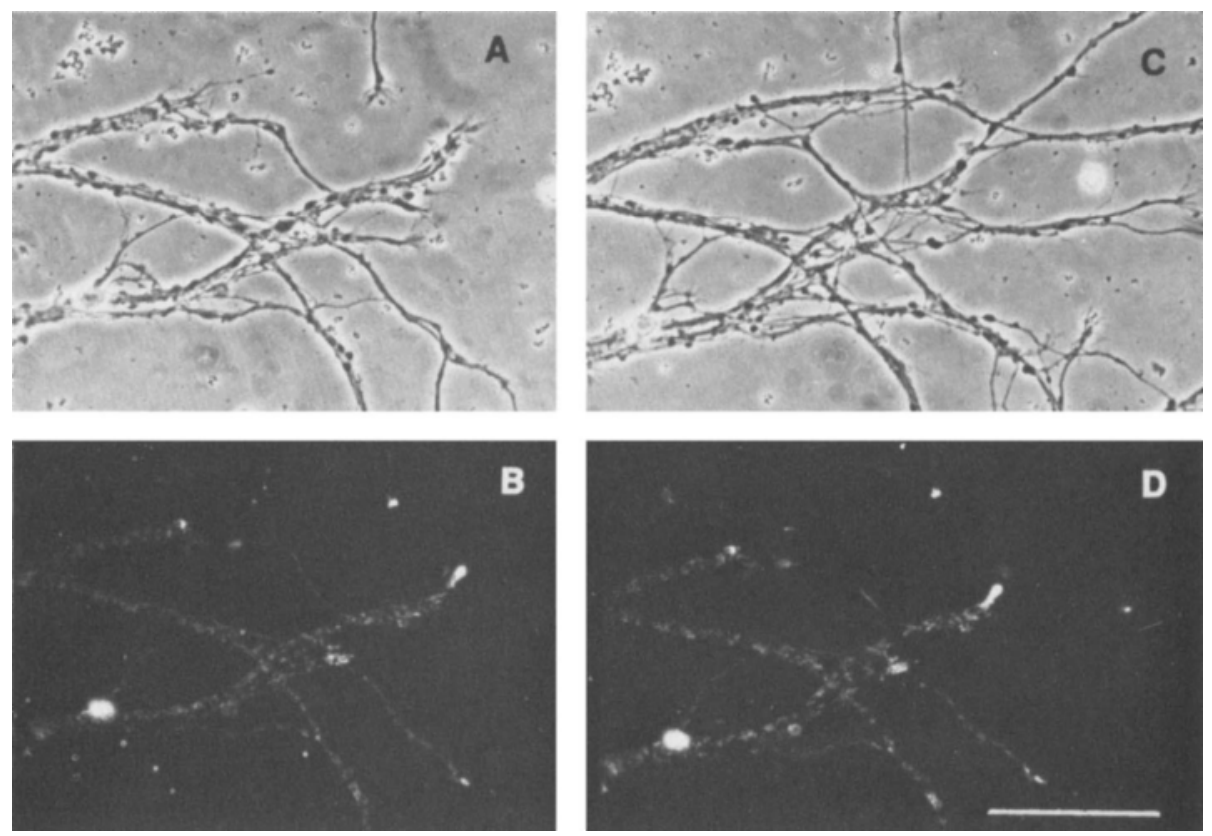

Fig. 3. Visualization of the addition of new neurite membrane with Rh-Con A. (A) Phase contrast photomicrograph of neurites incubated with $25 \mu \mathrm{g} / \mathrm{mL}$ of Rh-Con A followed by $100 \mu \mathrm{g} / \mathrm{mL}$ of anti-Con A. (B) Fluorescent photomicrograph of (A). (C) Phase contrast photomicrograph of the same area $24 \mathrm{~h}$ later. (D) Fluorescence photomicrograph of (C). Bar $=60 \mu \mathrm{m}$.

there is not only such a turnover of some preexisting membrane components, but a net increase of new membrane as well. Of special interest is the possibility of a localized site of membrane addition during nerve growth, whether proximally at the perikaryon, throughout the axon, or distally at the growing tip. While the various experimental approaches prior to the present study support the latter possibility, it was apparent that a demonstration of neurite growth under conditions in which old and new membrane could be clearly distinguished would help to clarify this issue.

The present study readdressed this question by examination of the behavior of preexisting neurite membrane Con A receptors under conditions in which sequential growth could be documented. Following binding of the Con $A$ to the cultures, anti-Con A was added to prevent lateral diffusion of the marker during the 24 -h growth interval. Only membrane that had been tagged $24 \mathrm{~h}$ previously with Con A/anti-Con A bound the fluorescent Rh-goat antirabbit IgG, while membrane that had been added during the 24 -h interval did not have the lectin/antilectin complex on its surface and consequently could not bind the fluorescent antibodies.

It should be kept in mind that although glycoproteins, many of which will bind Con $\mathrm{A}$, are prominent membrane components, their behavior is not necessarily typical of all of the constituents of the axolemma. The experimental approach used in these experiments necessarily involves perturbing the membrane and possibly underlying cytoplasmic elements to some extent. The persistence of intense lectin binding at the location of the $T_{0}$ growth cone after $24 \mathrm{~h}$ suggests that this may indeed be the case. It is clear, nevertheless, that only a fraction of the Con A receptors are bound while some membrane glycoproteins remain freely mobile. Furthermore, the lectin-antibody treatment does not prohibit neurite outgrowth during the 24 -h interval. 
With the experimental protocol outlined above, at least three alternative results could be predicted, each indicating a different site of membrane insertion: (1) labeling of regions of new growth distally with loss of proximal labeling, suggesting insertion of new membrane at the perikaryon; (2) presence of labeled Con $A$ receptors throughout the axon, indicating insertion along the growing fiber; or, (3) absence of label in distal regions of new growth, while proximal preexisting membrane remains labeled, suggesting insertion at or near the growth cone. The results shown in Figures 2 and 3 are clearly in accord with the third possibility.

While the observations reported here are consistent with the hypothesis that new membrane is added distally in the region of the growing tip, other explanations remain possible. For example, new membrane components added at the cell body or along the axon could travel down the neurite surface membrane, between the interstices of the immobilized Con A receptor aggregates, and be deposited at the tip. Such anterograde surface motion or axolemmal transport has not been documented, either by radioautographic or surface labeling studies. Electron microscopic radioautography following application of labeled precursors of protein or glycoprotein in both regenerating (Lentz, 1972; Tessler, AutilioGambetti, and Gambetti, 1977) and intact nerves (Droz and DiGiamberardino, 1974; Droz, Rambourg, and Koenig, 1975) has provided evidence for transport of membrane components within the axoplasm, possibly along the smooth endoplasmic reticulum, prior to insertion into the axolemma of the growth cone or nerve ending. Bray (1970) attached dye or glass particles to rat sympathetic ganglion cell neurites and found no movement of the markers as the fibers grew. Koda and Partlow (1976) have reported retrograde movement of Con A-coated red blood cells or polystyrene beads bound to neurites of chick sympathetic ganglia. Anterograde movement was seen only at the growth cone. The results of both of these experiments have been interpreted to support the hypothesis that new membrane is inserted at the growing tip. A similar conclusion was reached from recent studies of Pfenninger (1979) in which neurites and growth cones were tagged with unlabeled ricin (RCA I) followed a short time later by ferritin-RCA I. Electron microscopy revealed the ferritin-RCA I only in vesicle-filled mound regions of the growth cone, a result compatible with membrane addition at this locus.

While alternative explanations of the present results cannot be completely ruled out, the most parsimonious interpretation of this as well as previous studies is that new membrane is added in the region of the growing tip of the neurite.

This work was supported by grants NS 13743 (BWA) and NS 14565 (DA) from the National Institutes of Health. MS was supported by a fellowship from the Weizmann Institute of Science, Rehovot, Israel.

\section{REFERENCES}

AXELROD, D., KOPPEL, D. E., SCHLEssinger, J., ElsoN, E. L., and WEBB, W. W. (1976). Mobility measurement by analysis of fluorescence photobleaching recovery kinetics. Biophys. J. 16: 1055-1069.

BRAY, D. (1970). Surface movements during the growth of single explanted neurons. Proc. Natl. Acad. Sci. 65: 905-910.

Droz, B., and DiGiamberardino, L. (1974). Transport of macromolecules in nerve cells. In: Advances in Cytopharmacology 2, B. Ceccarelli, F. Clemente, and J. Meldolesi, Eds., Raven, New York, pp. 249-256.

Droz, B., Rambourg, A., and Koenig, H. L. (1975). The smooth endoplasmic reticulum: 
structure and role in the renewal of axonal membrane and synaptic vesicles by fast axonal transport. Brain Res. 93: 1-13.

EdELMAN, G. M. (1976). Surface modulation in cell recognition and cell growth. Science 192: $218-226$.

FELDMAN, E. L. (1979). Glycoconjugates in the regenerating goldfish visual system. Thesis, University of Michigan, Ann Arbor, MI.

Feldman, E. L., Axelrod, D., Schwartz, M., and Agranoff, B. W. (1979). New neurite membrane is added at the growing tip. Soc. Neurosci. Abstr. 5: 303.

FELDMAN, E. L., HEACOCK, A. M, and AGRANOFF, B. W. (1978). Lectin binding in the regenerating goldfish visual system. Soc. Neurosci. Abstr. 4: 531 .

KoDA, L. Y., and PARTlow, L. M. (1976). Membrane marker movement on sympathetic axons in tissue culture. J. Neurobiol. 7: 157-172.

LANDRETH, G. E., and AGRANOFF, B. W. (1979). Explant culture of adult goldfish retina: a model for the study of CNS regeneration. Brain Res. 161: 39-53.

LENTZ, T. L. (1972). Distribution of leucine $-{ }^{3} \mathrm{H}$ during axoplasmic transport within regenerating neurons as determined by electron-microscope radioautography. J. Cell Biol. 52: 719-732.

LETOURnEAU, P. (1975). Possible roles for cell-to-substratum adhesion in neuronal morphogenesis. Dev. Biol. 44: 77-91.

Pfenninger, K. H. (1979). Synaptic-membrane differentiation. In: The Neurosciences: Fourth Study Program, F. O. Schmitt and F. G. Worden, Eds., The MIT Press, Cambridge, MA, pp. 779-795.

Tessler, A. R., Autilio-GambetTi, L., and Gambetti, P. (1977). The distribution of axonally transported glycoproteins in regenerating axons. J. Neuropath. Exp. Neurol. 36: 634 .

THOMPSON, N. L., and AXELROD, D. (1980). Reduced lateral mobility of a fluorescent lipid probe in cholesterol-depleted erythrocyte membrane. Biochim. Biophys. Acta 597: 155-165. 